\title{
Correction to: Estimation of static earth pressures for a sloping cohesive backfill using extended Rankine theory with a composite log-spiral failure surface
}

\author{
Shi-Yu Xu ${ }^{1}$ (D) Abiodun Ismail Lawal ${ }^{1} \cdot$ Anoosh Shamsabadi $^{2} \cdot$ Ertugrul Taciroglu $^{3}$
}

Published online: 30 May 2018

(c) Springer-Verlag GmbH Germany, part of Springer Nature 2018

\section{Correction to: Acta Geotechnica}

https://doi.org/10.1007/s11440-018-673-2

In the original publication of the article, the left-hand side of Eq. (8) had been mistakenly changed to $\sigma_{c}$ instead of $\sigma_{x}$. The correct equation should read as given below:

$$
\begin{aligned}
& \sigma_{x}=\gamma z \cos ^{2} \beta \\
& \frac{[1-2(c / \gamma z) \tan \phi]\{\cos \beta+j \sqrt{\Delta}\}-2(c / \gamma z)^{2} / \cos \beta}{(\cos \beta-j \sqrt{\Delta})}
\end{aligned}
$$

The original article has been corrected.

The original article can be found online at https:// doi.org/10.1007/s11440-018-0673-2.

Shi-Yu Xu

shiyuxu@cityu.edu.hk

Abiodun Ismail Lawal

ailawal2-c@my.cityu.edu.hk

Anoosh Shamsabadi

anoosh.shamsabadi@hsr.ca.gov

Ertugrul Taciroglu

etacir@ucla.edu

1 Architecture and Civil Engineering Department, City University of Hong Kong, Kowloon, Hong Kong SAR

2 Caltrans, Office of Earthquake Engineering, Sacramento, CA 95816, USA

3 Civil and Environmental Engineering Department, University of California, Los Angeles, CA 90095, USA 